\title{
An Anatomical Study of Variations of Sacral Hiatus and Its Clinical Correlation.
}

\author{
Dr.Rita Kumari ${ }^{1}$, Dr.Shobha Kumari ${ }^{1}$, Mrs.Atulya Prasad, N.Jaques Britto ${ }^{1}$, \\ Dr.Subratanag ${ }^{2}$ \\ ${ }^{1}$ Department of Anatomy, AIIMS Patna, Bihar, India. \\ ${ }^{2}$ Department of Anaesthesia, NMCH, Rohtas, Bihar, India.
}

\begin{abstract}
Sacrum is a triangular bone formed by fusion of five sacral vertebrae (S1-S5). It forms the lower part of vertebral column. The opening present at the lower end of sacral canal is known as sacral hiatus. It is formed by failure of fusion of lamina of fifth sacral vertebra in midline. Shape and extent of the sacral hiatus is variable. So our study is directed to find out such variations. The remnants of the inferior articular process of S5 elongates downward on both sides of the sacral hiatus. These two bony process are known as sacral cornua (horns). It is very important landmark to locate the sacral hiatus during caudal epidural anaesthesia and analgesia. In our present study we have summarised the variations in the sacral hiatus according to its shape and extent.
\end{abstract}

Keywords: Sacral hiatus, sacral cornua, caudal epidural anaesthesia.

\section{Introduction}

Sacrum is a large triangular bone formed by fusion of five sacral vertebrae and forms the lower part of vertebral column. Cranially it articulates with lumbar vertebra and caudally it articulates with coccyx. Vertebral foramina of sacrum is known as sacral canal. It contains cauda equine, spinal meninges, sacral and coccygeal nerve roots. The opening present at the lower end of the sacral canal is known as sacral hiatus.Its shape is variable but generally it is triangular in shape with apex upward and base downward. It contains fifth pair of sacral nerve, coccygeal nerve and filum terminale. Sacral hiatus is formed due to failure of fusion of lamina of fifth (sometimes fourth) sacral vertebrae. It is located inferior to fourth $\left(\right.$ or $3^{\text {rd }}$ ) fused sacral spines or lower end of median sacral crest. If the lamina of the higher sacral vertebrae are not fused then hiatus will be seen at a higher level .Sometimes non fusion of all the five lamina of sacrum is observed posteriorly which will present a midline gap. This condition is observed in spina bifida. Spina bifida is a developmental defect of vertebral column in which the laminae of one or more vertebrae fail to fuse. It is of two types spina bifida occulta and spina bifida cystica. Spina bifida cystica is again of two types meningocele and myelomeningocele. Sometimes spina bifida with myeloschisis is also seen. Most common site of spina bifida is lumber and sacral region.

The remnants of inferior articular process of fifth sacral vertebra projects downward on both sides of sacral hiatus which is known as sacral cornua (horn). It is very important landmark to locate the sacral hiatus during caudal epidural anaesthesia. Caudal epidural anaesthesia is most popular regional anaesthesia used in children. Caudal approach of epidural anaesthesia is done through sacral hiatus. Lots of variations are found in anatomy of sacral hiatus which leads to failure of caudal epidural block. Tsui et al studied that caudal epidural block has $25 \%$ failure rate. So awareness of the anatomical variation like absence of sacral hiatus and narrowing of sacral canal is needed for successful anaesthetic procedures. Caudal epidural block is used for anaesthesia and analgesia below umbilicus in young ages and in urgent procedures like incarcerated hernia, perineal procedure, lower limb surgery and in superficial operations such as skin grafting.

Material and methods: The study was conducted in department of anatomy, Aiims, Patna. We studied over 42 sacra with undetermined sex and age. Damaged bones were excluded from study. We studied different features of sacrum like the shape and extent of sacral hiatus. Level of apex and base of sacral hiatus were noted and photographs were taken for variable findings of the sacrum. Then we summarised our study.

Observation: In our present study we found a lots of variation in shape and extent of sacral hiatus. All our findings are disused under following headings.

Apex of sacral hiatus: In all the sacra the level of sacral hiatus was noted. Many variations in the level of apex were found. The apex of sacral hiatus extends between $2^{\text {nd }}$ to $5^{\text {th }}$ sacral vertebra. In present study one (2.3\%) sacrum (fig 1) was found in which all the lamina was unfused leading to an open sacral canal (spina bifida). None of sacrum have apex of hiatus at the level of S2.In one specimen (fig 2) lamina of S1 was unfused and lamina of S2 was fused and below that all the lamina was unfused. So in this specimen apex of sacral hiatus was at S3 level. In (fig 3) level of apex of sacral hiatus was found at level of S3, thus in 2 (4.76\%)specimens 
level of apex is at S3.Level of apex of sacral hiatus at S4 found in 34 (80.95\%) sacra( fig 4). At the level of S5 apex of sacral hiatus was found in $3(7.14 \%$ ) cases (fig 5).Sacral hiatus was absent but a narrow sacral canal was present in $2(4.76 \%)$ sacra (fig 6).

\begin{tabular}{|c|c|}
\hline Level of the vertebra at which the apex of sacral hiatus was found & Percentage of occurrence \\
\hline Unfused & $2.38 \%$ \\
\hline S2 & 00 \\
\hline S3 & $4.76 \%$ \\
\hline S4 & $80.95 \%$ \\
\hline S5 & $7.14 \%$ \\
\hline Absent sacral hiatus & $4.76 \%$ \\
\hline
\end{tabular}

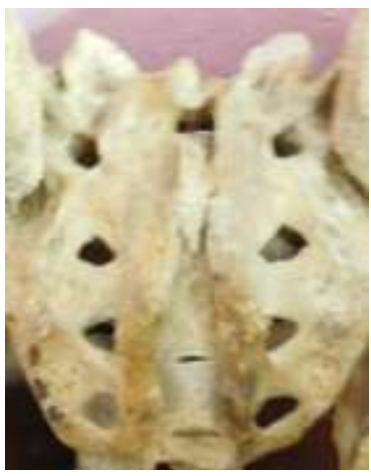

fig-1

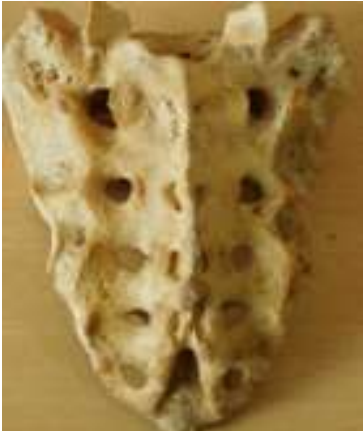

fig-4

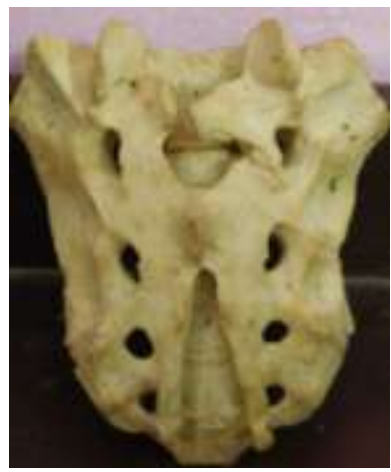

fig-2

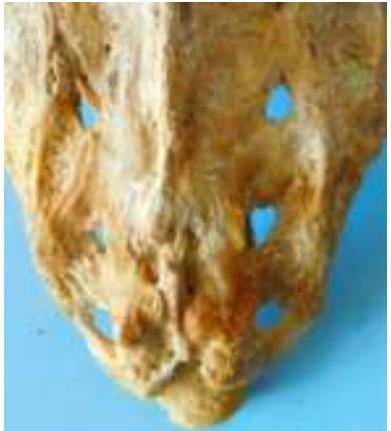

fig-5

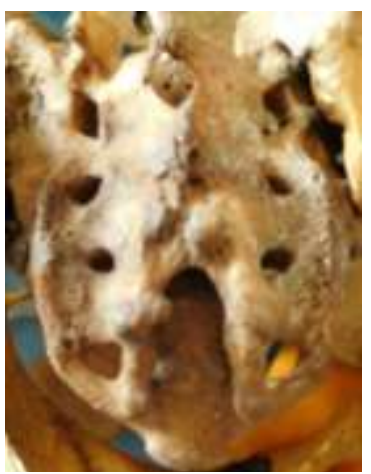

fig-3

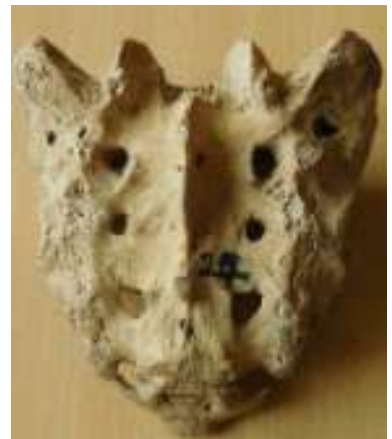

fig-6

Base of sacral hiatus: The base of sacral hiatus was noted with respect to sacral vertebra and the level of base was found between $4^{\text {th }}$ and $5^{\text {th }}$ sacral vertebra. No cases were foundat the level of $2^{\text {nd }}$ and $3^{\text {rd }}$ vertebra. In one specimen (fig 1) base was not considerable because it had complete spina bifida. In two sacra (fig 6) sacral hiatus was absent so base is also not found in these specimens. In rest 39 sacra base was at the level of S5.

Shape of sacral hiatus: Altos of variations were noted in the shape of sacral hiatus. In our present study inverted $\mathrm{U}$ was the commonest shape of sacral hiatus and $\mathrm{M}$ shaped was the rarest finding. We found inverted $\mathrm{U}$ shaped sacral hiatus in $17(40.47 \%)$ cases( fig 7), inverted V shaped sacral hiatus in $14(33.33 \%)$ cases (fig 8), some bony projections from lateral sides were visible in both $\mathrm{U}$ and $\mathrm{V}$ shaped hiatus, irregular shape in 9 $(21.42 \%)$ sacra(fig 9) and $M$ shaped in $2(4.76 \%)$ cases(fig 10).

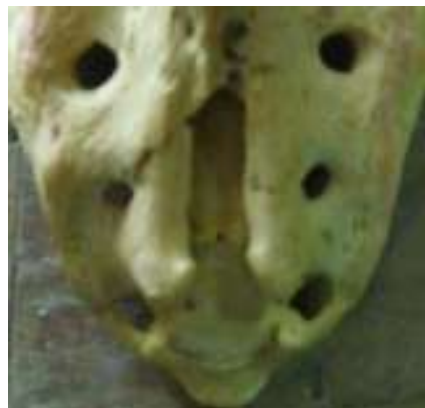

Fig -7

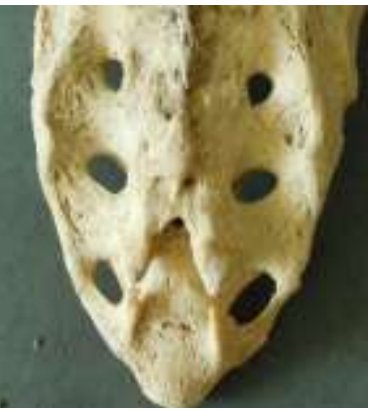

fig -8

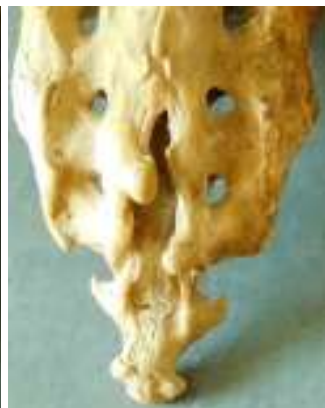

fig- 9

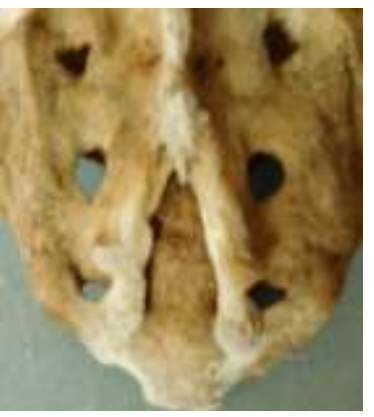

fig- 10 


\section{Discussion}

The sacrum develops from the fusion of five sacral vertebrae. Each half of the vertebral arch fuse posteriorly to form complete sacral canal. Lamina of $5^{\text {th }}$ sacral vertebra fails to fuse posteriorly and thus form sacral hiatus. Sacrum exhibit many variationsespecially in sacral hiatus. Shape and extent of the hiatus depends on the number of laminae that fails to fuse in the midline posteriorly.

Different levels of apex of sacral hiatus were noted in the present study with respect to sacral vertebrae. Most commonly it was found at the level of $4^{\text {th }}$ sacral vertebra.

Table 2 : Level of apex

\begin{tabular}{|l|l|l|l|l|l|}
\hline Sl. No. & Level of Apex & $\begin{array}{l}\text { Vinod kumar et al } \\
(1992)\end{array}$ & Nagar S.K.(2004) & $\begin{array}{l}\text { Sekiguchi M et } \\
\text { al(2004) }\end{array}$ & $\begin{array}{l}\text { V.k. Shinde et } \\
\mathrm{al}(2016)\end{array}$ \\
\hline 1. & $2^{\text {nd }}$ sacral vetebra & $4.95 \%$ & $3.40 \%$ & $4 \%$ & $1.03 \%$ \\
\hline 2. & $3^{\text {rd }}$ sacral vertebra & $8.91 \%$ & $37.3 \%$ & $15 \%$ & $17.52 \%$ \\
\hline 3. & $4^{\text {th }}$ sacral vertebra & $76.23 \%$ & $55.90 \%$ & $65 \%$ & $79.38 \%$ \\
\hline 4. & $5^{\text {th }}$ sacral vertebra & $7.43 \%$ & $3.40 \%$ & $15 \%$ & $2.06 \%$ \\
\hline
\end{tabular}

In our present study one sacrum was found to have unfused lamina having an open sacral canal (spina bifida). None of the sacrum showed sacral hiatus at S1 and S2. In $4.76 \%$ of sacrum was having hiatus at the level of S3, $80.95 \%$ at S4 and $4.76 \%$ at S5 vertebra, in $4.76 \%$ the sacral hiatus was absent but narrow sacral canal was present. These difference may be because of study in different populations, the environmental and nutritional factors which results in such anomalies like spina bifida.

In present study the shapes of sacral hiatus were variable. Most common was inverted U found in 17 $(40.47 \%)$ cases. Inverted V in14 (33.33\%), irregular in $9(21.42 \%)$ and $\mathrm{M}$ shaped in $2(4.76 \%)$ sacra.

Kumar et al (2009) noted various shapes of sacral hiatus the most common being inverted V $(76.23 \%)$ and inverted $\mathrm{U}$ in $27.51 \%$, in $7.43 \%$ dumbell shaped.

Table 3: showing comparison between different studies regarding shapes of the sacral hiatus

\begin{tabular}{|l|l|l|l|l|}
\hline sl. no. & Study by Authors & Inverted U shape(\%) & Inverted V shape(\%) & Irregular (\%) \\
\hline 1. & Nadeem et al & 56 & 14 & 16 \\
\hline 2. & Nagar et al & 41.5 & 27 & 14.1 \\
\hline 3. & Osunwoke et al & 24.1 & 33.3 & 13 \\
\hline 4. & Qudusia et al & 62.37 & 22.16 & 8.76 \\
\hline 5. & Seema et al & 42.95 & 27.51 & 16.10 \\
\hline 6. & Deepa S et al & 57.5 & 25 & 17.5 \\
\hline
\end{tabular}

In present study there was complete agenesis of dorsal bony wall of sacral canal in one ( $2.38 \%$ ) sacrum (spina bifida). Open sacral canal ( spina bifida) reported by other workers namely $11.8 \%$ by Trotter et al , $1.49 \%$ by kumar et al (2009) and $1.5 \%$ by nagar (2004).

The sacral hiatus is a variable space through which caudal epidural anaesthesia is given for various purposes. The sacral cornua are bony landmark to locate the sacral hiatus. Edward et al (1942) for the first time used sacral hiatus for continuous caudal analgesia during labour. One of factor of caudal epidural block failure is anatomical variations of sacral hiatus like absent or narrow sacral hiatus. The sacral hiatus is important landmark to perform caudal epidural block for treating patient with low back pain.

\section{Conclusion}

The sacral hiatus shows many variations in shape and extent of sacral hiatus. Awareness of these variations are very important for orthopedicians, surgeons and anesthetists because success of caudal epidural anaesthesia and analgesia depends on it. The detail anatomical knowledge of variations of sacral hiatus is very helpful for the anaesthetists to inceased success rate of caudal anaesthesia.

\section{References}

[1]. Standring S,Newell RLM, Collins P, Healy JC; Grays Anatomy, The anatomical basis of clinical practice. 40 edt.SPAIN,CHURCHILL Livingstone Elsevier,2008;pp724-728.

[2]. Faruqui NA. Human osteology. 2nd ed. New Delhi:CBS Publishers ; 2000. P. 206-214.

[3]. Trotter M, Letterman GS. Variations of the femalesacrum; their significance in continuous caudalanalgesia. Surg Gynaecol obstet 1994;78(4):419-424

[4]. Edwards WB, Hingson R. Continuous caudal anaesthesia in obstetrics. Am J Surg 1942;57: 459-464.

[5]. Moore KL, Dalley AF. Clinically oriented anatomy.5th ed. Philadelphia: Lippincott Williams and wilkins; 2006.P.490-495.

[6]. Vinod kumar et al. Morphometrical study of sacralhiatus. J Anat soc India 1992;41(1):7-13.

[7]. Nagar SK. A study of sacral hiatus in dry humansacra. J Anat Soc India 2004;53(2):18-21.

[8]. Sekiguchi M, Yabuki S. Satoh K, Kikuchi S. An AnatomicStudy of the sacral hiatus: A basis for successfulcaudal epidural block. Clin J. Pain2004;20(1):51-54.

[9]. Sinha MB , Rathore M , Sinha HP . A study of variation of sacral hiatus in dry bone in central indian region : International J . of healthcare and biomedical research $2014 ; 2(4)$ : pp46-52. 
[10]. Thejeswari , kumar S.Study of the level at which the sacral hiatus opens in south indian population:International journal of science and research 2014;3(7):pp547-548: ISSN: 2319-7064.

[11]. Shinde VK, Shirbadgi SA. Study of variations in levels of sacral hiatus.International journal of anatomy and research2016;4(1):1882-85. 